\title{
The Effect of Laparoscopic Sleeve Gastrectomy and Gastric Bypass Surgery on Non-Alcoholic Steatohepatitis in Iranian Patients with Obesity
}

Fezzeh Elyasinia ${ }^{1}$, Seyed Mehdi Jalali ${ }^{2}$, Soroush Zarini ${ }^{3}$, Ehsan Sadeghian ${ }^{1, *}$, Ahmadreza Sorush $^{1}$, Amirhossein Pirouz ${ }^{1}$

1. Department of Surgery, Shariati Hospital, Tehran University of Medical Sciences, Tehran, Iran

2. Department of Surgery, Vali-EAsr Hospital, Tehran University of Medical Sciences, Tehran, Iran

3. Department Surgery, Imam Khomeini Hospital, Tehran University of Medical Sciences

\footnotetext{
* Corresponding Author:

Ehsan Sadeghian, MD

Shariati Hospital, Jalal-e-Al-e-Ahmad Hwy, Tehran, Iran

Tel: + 982184902455

Fax: + 982188633039

Email: ehsan810@yahoo.com

Received: 20 Dec. 2020

Accepted: 07 May 2021
}

\author{
ABSTRACT
}

\section{BACKGROUND}

Non-alcoholic steatohepatitis (NASH) is a serious comorbidity in patients with obesity and because of the high risk of cirrhosis and the extreme mortality rate of NASH, approaching effective treatment methods, and improvements are crucial. Following few studies comparing the impact of laparoscopic gastric bypass (LGB) and laparoscopic sleeve gastrectomy (LSG) surgery on NASH, our study was conducted to assess the effect of these two surgical methods separately in patients with NASH through ultrasonography, and concurrently, on other factors such as lipid profiles and blood pressure to reduce the complications of complex obesity surgeries on patients and also provide a solution to prevent NASH-related cirrhosis.

\section{METHODS}

This study was performed at Imam Khomeini Hospital Complex; Vali-e-Asr Hospital affiliated to Tehran University of Medical Sciences.All patients with obesity who had undergone bariatric surgery at Vali-e-Asr Hospital during 2017 and 2018 were included in this prospective cohort study. Weight, body mass index (BMI), blood pressure, Alanine transaminase(ALT), Aspartate transaminase(AST),lipid profile and Fasting blood sugar(FBS)were evaluated before and one year after surgery. The patients underwent an ultrasound examination before surgery to determine the fatty liver grade. The type of operation (sleeve or bypass) was governed by the patient him/herself after receiving thorough clarifications about the available methods, their complications, and expected outcomes. In addition, by the separation of fatty liver grading with ultrasound modality, the correlation between ultrasound grading, laboratory results, and the rate of weight loss in patients who undergone both sleeve and bypass surgeries were evaluated and compared during a one-year follow-up.

\section{RESULTS}

In this study, 44 patients were included. 22 patients underwent laparoscopic sleeve gastrectomy (LSG), and 22 patients underwent laparoscopic gastric bypass (LGB) surgery. The mean age of the patients was $40.45 \pm 12.01$ years 35 patients (79.5\%) were women, and 9 patients (20.5\%) were men. Most patients (81.8\%) had grade I and II in terms of preoperative liver ultrasonography results. Bariatric surgery (LSG and LGB) greatly enhanced NASH's hepatic status in liver ultrasonography. Since the liver status of patients with preoperative ultrasonography was not significantly different between the two groups, there was no substantial distinction among the two groups in this regard, postoperatively. Weight and BMI, lipid profile, liver enzymes, FBS, and mean arterial blood pressure (MAP) were significantly reduced individually in both groups and all patients one year after surgery. None of the postoperative variables and their modifications had a prominent difference between the two groups except for Highdensity lipoprotein(HDL)level after surgery. The postoperative HDL was considerably higher in the LGB group ( $p=$ 0.014). However, the changes in HDL were not statistically different between both groups. The levels of AST, ALT, total cholesterol, LDL, and FBS were associated with the NASH grade.

\section{CONCLUSION}

Both types of LSG and LGB bariatric surgeries have been shown to significantly reduce BMI and improve lipid profiles, liver enzymes, and blood glucose levels in patients one year after surgery. The NASH status was also ameliorated considerably. The two types of surgery were not remarkably different in these modifications. Besides, there was a significant correlation between AST, ALT, total cholesterol, LDL, and FBS levels with the NASH grade.

\section{KEYWORDS:}

Obesity, Bariatric surgery, Gastric bypass, Sleeve gastrectomy, NASH

\section{Please cite this paper as:}

Elyasinia F, Jalali SM, Zarini S, Sadeghian E, Sorush AR, Pirouz AH. The Effect of Laparoscopic Sleeve Gastrectomy and Gastric Bypass Surgery on Non-Alcoholic Steatohepatitis in Iranian Patients with Obesity. Middle East J Dig Dis 2021;13:199-206. doi: 10.34172/ mejdd.2021.226. 


\section{INTRODUCTION}

Non-alcoholic fatty liver disease (NAFLD) is a common causes of chronic liver disease, which is growing worldwide. Approximately $30 \%$ of the world's population has NAFLD, of whom 5\% have non-alcoholic steatohepatitis (NASH), and about $20 \%$ suffer from liver cirrhosis. The main mechanism of NAFLD is insulin resistance, and its major risk factors are obesity, diabetes, and arterial hypertension. ${ }^{1}$ Obesity and metabolic syndrome are increasing predictors of fatty liver disease, and then the NAFLD/ NASH pervasiveness and associated complications are anticipated to expand in the future. ${ }^{2}$ Based on a recent investigation, the prevalence of NAFLD in Iran has been $2.09 \%$ to $2.9 \% .{ }^{3}$ Ultrasonography is used for the diagnosis and identification of fatty liver as the primary imaging and for screening asymptomatic patients with excessive liver enzymes that are suspected of having NASH. This method does not require radiation and costs much for patients. Thus, it is a non-invasive and effective diagnostic method for fatty liver disease. ${ }^{4}$

Some studies in patients with obesity have shown that bariatric surgery has improved hepatic steatosis, inflammation, fibrosis scores, and complete recovery from non-alcoholic steatohepatitis. ${ }^{5}$ Bariatric surgery, in which the structure of the gastrointestinal tract is modified to treat overweight, is considered to be one of the most successful treatments in recent years.the effectiveness of such operations to decrease weight-related comorbidity and the overall reduction of excess weight by more than $60 \%$ have been proven. ${ }^{6,7}$ Surgical procedures used to treat obesity include sleeve gastrectomy (SG), laparoscopic adjustable gastric banding (LAGB), Rouxen-Y gastric bypass (RYGB), biliopancreatic diversion (BPD), and one of the most popular one $(65.1 \%$ of all surgeries), which is the mini-gastric bypass (MGB). ${ }^{8,9}$ LSG is currently considered to be a prominent bariatric surgery method for long-term weight loss and reduction of associated comorbidities, which is comparable to RYGB. Various factors affect the occurrence of complications in obesity surgeries; some of these factors are the type of operation and skill of the surgeon. ${ }^{10}$ Studies have shown that having underlying diseases also plays a major role in the development of postoperative complications. For instance, diabetes, sex, age, gastroesophageal reflux disease, family history of cancers, and finally, the findings of lab- oratory tests and patient's endoscopy are useful in determining the type of procedure and avoiding complications. ${ }^{11,12}$ Due to its substantial improvements, bariatric surgery is regarded as one of the key therapies for obesity. In this study we aimed to evaluate and compare the impact of two common bariatric surgeries (LSG, LGB) on NASH via ultrasound diagnosis and biochemical assessment in 1-year follow-up.

\section{MATERIALS AND METHODS}

\section{Study Design and Patients}

This study was conducted at Imam Khomeini Hospital Complex, Vali-e-Asr Hospital affiliated to Tehran University of Medical Sciences during 2017 and 2018. In this prospective cohort study, all patients with obesity who underwent bariatric surgery in the Vali-e-Asr Hospital surgery center and met the following criteria were included in our study: 1) Body mass index (BMI) $\geq 40$ or $\mathrm{BMI} \geq 35$ with a comorbid disease (hypertension or DM) 2) No medical or physiological contraindications for bariatric surgery 3 ) At the time of the study, they did not drink too much alcohol (at least $20 \mathrm{gr} / \mathrm{d}$ for women and $30 \mathrm{gr} / \mathrm{d}$ for men) and during their lifetime, at no point in the last 20 years, consumed high alcohol for more than 2 years (according to the above criteria) 4) No long history of taking hepatotoxic drugs 5) Absence of chronic liver disease (such as hepatitis $\mathrm{B}$ and $\mathrm{C}$, and hemochromatosis) and 6) Age over 18 years.

Indications for surgeries were assessed based on the inclusion criteria as well as dietary period. The type of surgery (sleeve or bypass) was determined by the patient himself after receiving a full explanation about the available methods, risks, and predictable outcomes. The following criteria that were evaluated before and one year after surgery included: Weight, BMI, blood pressure,ALT,AST,lipid profile, and FBS. Before surgery, the patients underwent ultrasonography to examine the degree of fatty liver. In this study, ultrasonography was performed as the first step of imaging by the by a single radiologist, and the fatty liver was graded (0-III). After one year, the patients underwent ultrasound examination again. In addition to categorizing the grade of fatty liver with ultrasound modality, the correlation between ultrasound gradation, laboratory data, and weight loss rate in patients in both sleeve and bypass groups were assessed and also 


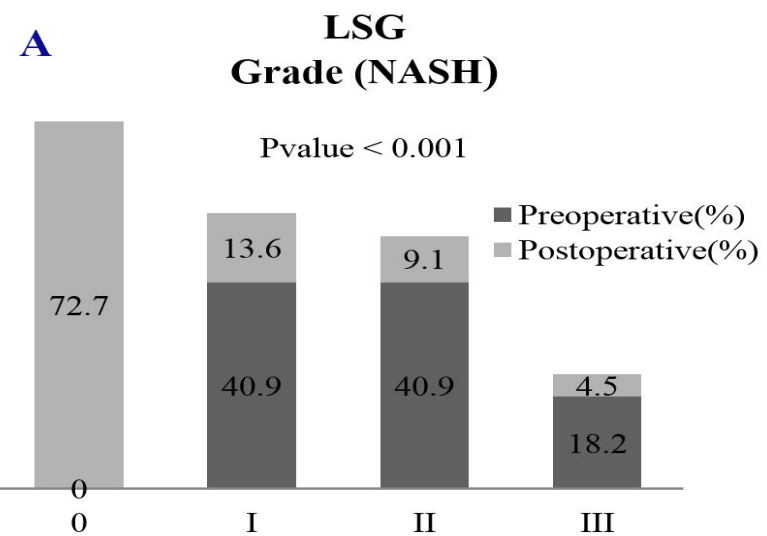

\section{$\mathbf{B}$ \\ LGB}

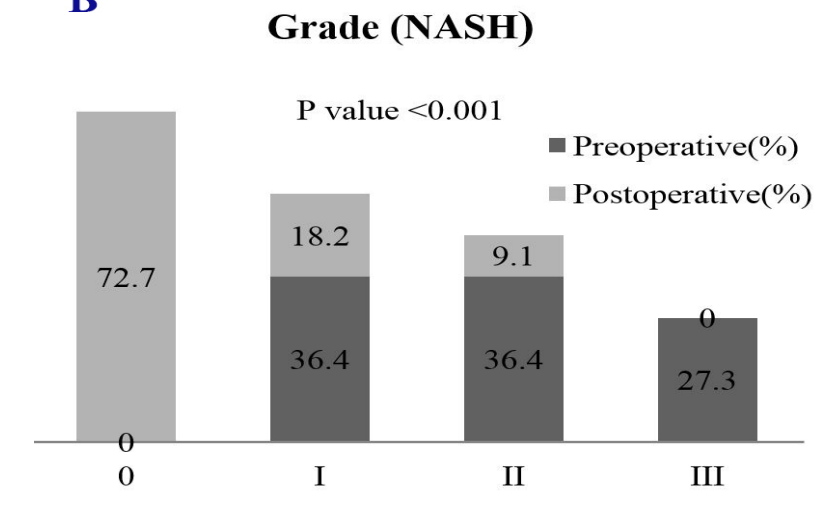

Fig. 1: Changes in ultrasonography results in LSG (a) and LGB (b) patients after one-year follow-up

compared during the one-year follow-up. Since a similar former study comparing the reduction of NASH in LSG and RYGB surgeries was not reported, the sample size determination method was used as a pilot study. Previous studies have shown that through bariatric surgery, the decline in NASH is approximately $85 \%$ (considering $\mathrm{Z}$ equals 1.96 , d equals 0.165 , and alpha 0.05 ) [-N $=\mathrm{Z} 21$ $\alpha / 2 \mathrm{P}(1-\mathrm{P}) / \mathrm{d} 2=19)]$ the sample size for the initial study (plus $10 \%$ loss-withdrawal) were 20 patients in each group and then due to the significant difference in liver grade after one year, it was shown that the same sample size was sufficient.

\section{Statistical Analysis}

Mean \pm standard deviations (SD) were used to display quantitative variables with normal distribution and frequency (\%) to show qualitative variables. Qualitative variables were analyzed using the Chi-squared test, and quantitative variables with normal distribution were analyzed using Student's $t$ test. ANOVA was used to compare data of more than two groups. Quantitative variables with abnormal distribution were also measured by Mann-Whitney test. A comparison of quantitatively abnormal variables before and after surgery was performed by Wilcoxon Signed Ranks test. The normality of the distribution of the variables was measured using the Shapiro-Wilk test. The relationship between NASH grade in ultrasonography and other slightly abnormal variables was measured by the Kruskal-Wallis test. The correlation between NASH grade in ultrasonography before and after surgery with other variables was determined by the Pearson correlation coefficient. In all analyzes, the results were significant at $p$ value $<0.05$

\section{RESULTS}

This study included a total of 44 patients, 22 of whom underwent LSG and the remaining 22 patients underwent LGB. The mean age of the patients was $40.45 \pm 12.01$ years. 35 (79.5\%) patients were women, and 9 (20.5\%) were men. Other demographic and preoperative features of the patients are shown in tables $1 \& 2$. As can be seen, none of the patients' preoperative characteristics were substantially different between the two surgical groups. Based on preoperative liver ultrasonography results, most patients $(81.8 \%)$ had grade I and grade II. In this respect, the two groups of surgery had no difference.

The results of the ultrasonography were compared before and one year after surgery. Bariatric surgeries (LSG and LGB) significantly improved the patient's liver status on liver ultrasonography concerning to non-alcoholic steatohepatitis. $72.7 \%$ of the patients had no NASH signs on ultrasonography one year after surgery. The effects of NASH on liver ultrasonography had also improved for each of the two types of surgeries (Figure 1). The liver status of the patients with preoperative and also postoperative ultrasonography was not significantly different in this regard (Figure 2). As it is shown in table 2, one year after surgery, weight $(p<0.001)$ and BMI $(p<0.001)$ had a noticeable decrease in the two groups separately and in all patients. In each LSG and LGB patients, and all patients, there was no significant change in the lipid profile after one year. LDL level was also not significantly reduced in patients with LSG, but remarkably decreased in patients with LGB and all patients. Other factors of 
Table 1: Comparison of demographic characteristics of the patients between the two surgical groups

\begin{tabular}{|c|c|c|c|c|}
\hline Group & LSG (N= \%) & LGB (N=\%) & Total $(\mathrm{N}=\%)$ & $P$ value \\
\hline Sex (female) & $18(81)$ & $17(77.3)$ & $35(79.5)$ & 0.709 \\
\hline Sex (male) & $4(18.2)$ & $5(22.7)$ & $9(20.5)$ & \\
\hline Hypertension & $5(22.7)$ & $2(9.1)$ & $7(15.9)$ & 0.216 \\
\hline Diabetes mellitus & $5(22.7)$ & $7(31.8)$ & $12(27.3)$ & 0.498 \\
\hline Asthma & $0(0)$ & $1(4.5)$ & $1(2.3)$ & 0.312 \\
\hline Fatty liver & $10(45.5)$ & $9(40.9)$ & $19(43.2)$ & 0.761 \\
\hline \multicolumn{5}{|l|}{ Fatty liver grade } \\
\hline Grade I & $9(40.9)$ & $8(36.4)$ & $17(38.6)$ & 0.772 \\
\hline Grade II & $9(40.9)$ & $8(36.4)$ & $17(38.6)$ & \\
\hline Grade III & $4(18.2)$ & $6(27.3)$ & $10(22.7)$ & \\
\hline Hepatitis & $0(0)$ & $0(0)$ & $0(0)$ & \\
\hline Perioperative surgical history & $7(31.8)$ & $10(45.5)$ & $17(38.6)$ & 0.354 \\
\hline
\end{tabular}

Table 2: Comparison of preoperative and postoperative quantitative variables and their changes between the two surgical groups

\begin{tabular}{|c|c|c|c|c|c|c|c|}
\hline \multirow[t]{2}{*}{ Variables } & \multicolumn{2}{|c|}{ Preoperative } & \multirow[t]{2}{*}{$P$ value } & \multicolumn{2}{|c|}{ Postoperative } & \multirow[t]{2}{*}{$P$ value } & \multirow{2}{*}{$\frac{P \text { value }}{\text { shifts }}$} \\
\hline & LSG (N = 22) & LGB (N = 22) & & LSG $(N=22)$ & LGB (N = 22) & & \\
\hline Weight (kg) & $114.3 \pm 17.5$ & $122 \pm 18.5$ & $0.136^{*}$ & $87.9 \pm 17.5$ & $92.8 \pm 18.5$ & 0.331 & $1.000 *$ \\
\hline $\operatorname{BMI}\left(\mathrm{kg} / \mathrm{m}^{2}\right)$ & $43.7 \pm 4$ & $43 \pm 4.6$ & $0.548 *$ & $33.8 \pm 11.6$ & $32.7 \pm 15.9$ & 0.557 & 0.733 \\
\hline $\operatorname{AST}(\mathrm{U} / \mathrm{L})$ & $31.6 \pm 14.3$ & $28.7 \pm 13.6$ & $0.549^{*}$ & $26.9 \pm 4.6$ & $23 \pm 6.8$ & $0.069^{*}$ & $0.732 *$ \\
\hline $\operatorname{ALT}(\mathrm{U} / \mathrm{L})$ & $26.5 \pm 10.2$ & $22.4 \pm 9.7$ & $0.196^{*}$ & $22.8 \pm 14.3$ & $18.7 \pm 13.6$ & $0.117^{*}$ & $0.897 *$ \\
\hline $\mathrm{TG}(\mathrm{mg} / \mathrm{dL})$ & $109.8 \pm 30.5$ & $95.2 \pm 23.5$ & 0.083 & $95.7 \pm 5.8$ & $89 \pm 7.1$ & 0.149 & $0.221 *$ \\
\hline Cholesterol (mg/dL) & $157.4 \pm 42.1$ & $159.1 \pm 39.2$ & 0.892 & $136 \pm 8.6$ & $150.6 \pm 6.9$ & 0.186 & $0.226^{*}$ \\
\hline LDL (mg/dl) & $99.1 \pm 19$ & $97.1 \pm 26.8$ & $0.613 *$ & $90.5 \pm 30.5$ & $91.9 \pm 23.5$ & $0.991 *$ & $0.842 *$ \\
\hline $\operatorname{HDL}(\mathrm{mg} / \mathrm{dl})$ & $42.2 \pm 5.7$ & $46.1 \pm 4.8$ & $0.059^{*}$ & $42 \pm 20.5$ & $46.6 \pm 15.7$ & $0.014 *$ & 0.685 \\
\hline FBS (mg/dl) & $117.7 \pm 30.5$ & $107.4 \pm 22.5$ & $0.278^{*}$ & $100.2 \pm 40.2$ & $93 \pm 31.3$ & 0.09 & 0.566 \\
\hline MAP (mmHg) & $98.3 \pm 11.2$ & $94.2 \pm 8.4$ & 0.178 & $92.5 \pm 19$ & $88.8 \pm 26.8$ & $0.299 *$ & 0.89 \\
\hline
\end{tabular}

Data are presented as mean \pm SD. *Mann-Whitney U test

SG, sleeve gastrectomy; GB, gastric bypass; BMI, body mass index; FBS, fasting blood sugar; TG, triglyceride; HDL, high-density lipoprotein;

LDL, low-density lipoprotein; AST, aspartate transaminase; ALT, alanine transaminase; MAP, mean arterial pressure

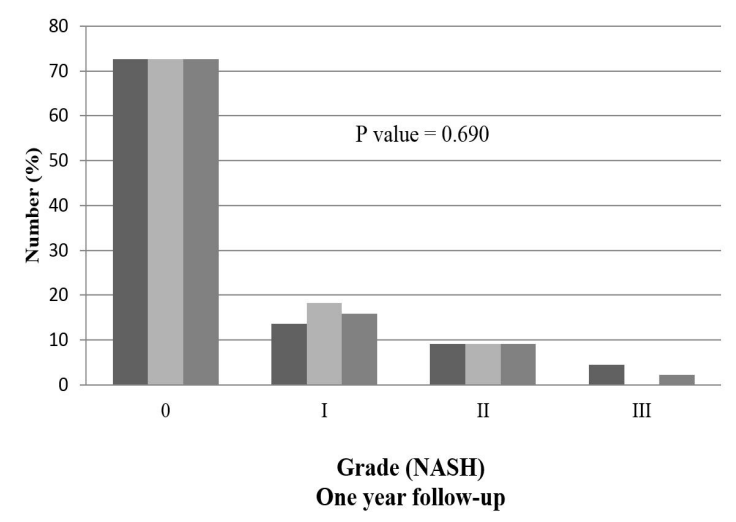

Fig. 2: Comparison of liver ultrasonography results of patients in the two surgical groups patients' lipid profile had a significant fall one year after surgery. The parameters of AST, ALT, FBS, and mean arterial pressure (MAP) substantially declined in the two groups as well as all patients. None of the postoperative variables and their changes was significantly different between the two groups except the level of postoperative - LGB HDL. The LGB group had a significantly higher post- Total operative HDL level $(p=0.014)$. In the following, we examined the factors related to the preoperative NASH ultrasound grade. As shown in table 3, before surgery, BMI, AST, ALT, LDL, FBS, and total cholesterol were significantly correlated with the grade of NASH, and as they increased, the severity of the disease increased. After surgery, only weight and weight loss were significant- 
Table 3: Relationship between preoperative and postoperative NASH grade in ultrasonography with quantitative variables and their changes

\begin{tabular}{|c|c|c|c|c|c|c|c|c|c|}
\hline \multirow{2}{*}{$\begin{array}{l}\text { Variables } \\
\text { Grade } \\
\text { (NASH) }\end{array}$} & \multicolumn{3}{|c|}{ Preoperative } & \multirow[b]{2}{*}{$p$ Value } & \multicolumn{4}{|c|}{ Postoperative } & \multirow[b]{2}{*}{$p$ Value } \\
\hline & I $(\mathrm{n}=17)$ & II (n=17) & III $(n=10)$ & & $0(n=32)$ & I $(n=7)$ & II $(n=4)$ & $\begin{array}{c}\text { III } \\
(n=1)\end{array}$ & \\
\hline $\begin{array}{l}\text { Weight } \\
(\mathrm{kg})\end{array}$ & $\begin{array}{c}115.9 \pm \\
19.9\end{array}$ & $\begin{array}{c}114.9 \pm \\
15.9\end{array}$ & $\begin{array}{c}127.6 \pm \\
17.5\end{array}$ & $0.151^{*}$ & $86.1 \pm 15.8$ & $96.2 \pm 10$ & $\begin{array}{c}109.2 \pm \\
15.3\end{array}$ & 107 & 0.02 \\
\hline $\begin{array}{l}\text { BMI } \\
\left(\mathrm{kg} / \mathrm{m}^{2}\right)\end{array}$ & $42.9 \pm 4.3$ & $42 \pm 3.7$ & $46.5 \pm 3.6$ & $0.017 *$ & $31.9 \pm 6.1$ & $36.8 \pm 2.1$ & $37 \pm 1.5$ & 38.9 & 0.066 \\
\hline $\begin{array}{l}\text { AST } \\
(\mathrm{U} / \mathrm{L})\end{array}$ & $23.4 \pm 11$ & $27 \pm 9.1$ & $47.2 \pm 11.2$ & $<0.001 *$ & $22.4 \pm 9.1$ & $26.1 \pm 10.2$ & $\begin{array}{c}37.7 \pm \\
23.8\end{array}$ & 47 & $0.079 *$ \\
\hline ALT (U/L) & $18.7 \pm 7.8$ & $23.9 \pm 9$ & $35 \pm 6.9$ & $<0.001 *$ & $18.9 \pm 6.5$ & $23.1 \pm 6.7$ & $\begin{array}{c}26.5 \pm \\
12.6\end{array}$ & 40 & $0.056^{*}$ \\
\hline $\begin{array}{l}\text { TG } \\
(\mathrm{mg} / \mathrm{dl})\end{array}$ & $\begin{array}{c}95.7 \pm \\
11.7\end{array}$ & $\begin{array}{c}105.5 \pm \\
36.7\end{array}$ & $109 \pm 30.5$ & $0.686^{*}$ & $90.9 \pm 15.8$ & $93.2 \pm 13.9$ & $\begin{array}{c}100.5 \pm \\
17.8\end{array}$ & 100 & 0.664 \\
\hline $\begin{array}{l}\text { Cholesterol } \\
(\mathrm{mg} / \mathrm{dl})\end{array}$ & $\begin{array}{c}141.2 \pm \\
29.2\end{array}$ & $\begin{array}{c}161.5 \pm \\
42.6\end{array}$ & $\begin{array}{c}181.7 \pm \\
42.3\end{array}$ & 0.034 & $141 \pm 34.5$ & $128.4 \pm 33.9$ & $\begin{array}{c}171.2 \pm \\
36.6\end{array}$ & 210 & 0.066 \\
\hline $\begin{array}{l}\mathrm{LDL} \\
(\mathrm{mg} / \mathrm{dl})\end{array}$ & $\begin{array}{c}89.3 \pm \\
14.8\end{array}$ & $\begin{array}{c}101.1 \pm \\
21.3\end{array}$ & $\begin{array}{c}108.1 \pm \\
32.6\end{array}$ & $0.078^{*}$ & $92.5 \pm 22.6$ & $75.8 \pm 18.9$ & $\begin{array}{c}105.2 \pm \\
17.8\end{array}$ & 100 & $0.143 *$ \\
\hline $\begin{array}{l}\text { HDL (mg/ } \\
\text { dl) }\end{array}$ & $43.2 \pm 4.8$ & $45 \pm 6.4$ & $44.5 \pm 5.6$ & 0.641 & $44 \pm 6.7$ & $45.4 \pm 5.2$ & $42.7 \pm 6$ & 52 & $0.366^{*}$ \\
\hline $\begin{array}{l}\text { FBS } \\
(\mathrm{mg} / \mathrm{dl})\end{array}$ & $\begin{array}{c}102.1 \pm \\
17.4\end{array}$ & $\begin{array}{c}115.2 \pm \\
32.9\end{array}$ & $\begin{array}{c}125.9 \pm \\
24.5\end{array}$ & $0.065^{*}$ & $95.4 \pm 13.8$ & $95.5 \pm 11.2$ & $\begin{array}{c}98.7 \pm \\
10.3\end{array}$ & 134 & $0.325^{*}$ \\
\hline $\begin{array}{l}\text { MAP } \\
(\mathrm{mg} / \mathrm{dl})\end{array}$ & $93.8 \pm 9.4$ & $97.6 \pm 9.9$ & $98.1 \pm 11.2$ & 0.438 & $90.7 \pm 9.8$ & $89.7 \pm 10.3$ & $\begin{array}{c}88.3 \pm \\
7.9\end{array}$ & 106.6 & $0.459 *$ \\
\hline $\begin{array}{l}\text { Weight } \\
\text { Loss }(\mathrm{kg})\end{array}$ & & & & & $30.3 \pm 14.4$ & $25.7 \pm 7.2$ & $\begin{array}{c}10.9 \pm \\
6.2\end{array}$ & 30 & $0.037 *$ \\
\hline
\end{tabular}

Data are presented as mean \pm SD. *Kruskal-Wallis Test

SG, sleeve gastrectomy; GB, gastric bypass; NASH, non-alcoholic steatohepatitis; BMI, body mass index; FBS, fasting blood sugar; TG, triglyceride; HDL, high-density lipoprotein; LDL, low-density lipoprotein; AST, aspartate transaminase; ALT, alanine transaminase; MAP, mean arterial pressure, 0 (normal), I (mild), II (moderate), III (severe)

ly related to the NASH grade, and patients with greater weight loss had lower NASH grade.

\section{DISCUSSION}

According to previous studies, the prevalence of $\mathrm{NASH}$ has been high in patients with obesity $(2.6 \%$ to $91 \%) .{ }^{13} \mathrm{NASH}$ appears to be an obesity-related disorder, with approximately half of the asymptomatic morbidly patients having histological NASH features. ${ }^{14}$ Aldoheyan and colleagues investigated the histological and biochemical effects of bariatric surgery on non-alcoholic fatty liver 3 months after surgery and reported a significant improvement in steatosis in more than half of the patients who had steatosis before surgery. ${ }^{15}$ Similarly, Clark and co-workers evaluated the histology of liver before and after gastric bypass surgery and demonstrated an enhancement in the histological features of NAFLD and steatosis in $81 \%$ of patients. ${ }^{16}$ Additionally, Furuya and others in their prospective study reported that steatosis and fibrosis disappeared in $89 \%$ of patients and $75 \%$ of patients, respectively, with $60 \%$ weight loss after RYGB surgery. As at the initial biopsy, liver biochemical variables such as lipid profile and blood glucose plasma concentration had been found within normal limits in $92.3 \%$ of the patients, and no difference was observed 2 years later. ${ }^{17}$ However, Mathurin and colleagues reported that NAFLD levels decreased in $95.7 \%$ of the patients with obesity, while fibrosis was slightly increased 5 years after bariatric surgery. ${ }^{18}$ In our research, bariatric surgery had a major impact on the liver status of patients, and $72 \%$ of the patients had no symptoms of NASH on liver ultrasonography 1 year after surgery. In this way, the two forms of gastric bypass and sleeve surgery were also not substantially different.

We may presume that the weight loss process after RYGB and MGB surgeries is indistinguishable; thus, there should be no contrasting outcomes for the surgical procedure. The mini-gastric bypass has been identified 
as a safe alternative to RYGB and has a good effect on weight loss and metabolic effects improvement. ${ }^{19,20}$ Laparoscopic sleeve gastrectomy and gastric bypass have been reported to be equally effective in terms of weight loss, quality of life, and complications 3 years after surgery. ${ }^{21}$ Nevertheless, in Milone and others' investigation, at 3-6 months follow-up, MGB was associated with a higher reduction in BMI compared with sleeve gastrectomy. The reduction of total cholesterol and triglycerides was also greater in MGB than SG. This indicates a correlation between BMI and changes in lipid profiles. ${ }^{22}$ In accordance with this, a prospective randomized study revealed RYGB had attained better-improved lipid profile in comparison with SG. ${ }^{23,24,25}$ Notwithstanding, Milone and colleagues demonstrated that during a 12-month followup, MGB and SG were completely comparable with improvements in lipid profile except for HDLc, which was higher in SG patients; this has been confirmed in other studies. $^{22,25,26,27,28}$ In line with that, in our study, weight, and BMI noticeably reduced one year after surgery. Triglycerides and total cholesterol had decreased considerably, but there was no substantial difference in both LDL and HDL levels. Only postoperative HDL was different between the two types of surgery and was higher in LGB; however, it was shown that changes in HDL levels in both surgeries were not significant.

Other clinical and biological characteristics, such as diabetes and sex, have also been shown to be significantly associated with $\mathrm{NASH},{ }^{29}$ although some studies indicate that the male sex, AST, ALT, and type 2 diabetes mellitus were independently correlated with NASH and advanced fibrosis. ${ }^{30,31}$ Likewise, Uslusoy and colleagues reported no association between ALT and AST levels, and hepatic fibrosis. ${ }^{32}$ On the contrary, it has been shown in our research that before surgery AST, ALT, and FBS had a significant relationship with the NASH grade. One year after surgery, liver enzymes decreased substantially in both groups, but there was no disparity among them in this regard. While liver enzymes are not ideal for accurate NAFLD status reflection, in most studies AST and ALT parameters have been used to determine the liver status before and after bariatric surgery. In a prospective controlled study, the long-term effect of bariatric surgery on transaminase levels was investigated, and significant changes in ALT levels and their correlation with weight loss at 2 and 10 years postoperatively were demonstrated. ${ }^{33}$ Moreover, Poppy and co-workers investigated the risk factors of BDP due to acute postoperative liver injury and AST level, which had been elevated after 2 months, decreased substantially 10 months after surgery. ${ }^{34}$ Similarly, Keshishian and others reported an increase in AST (130\%) and ALT (160\%) levels 6 months after (BPD/DS). Nonetheless, these values returned to normal level after one year and did not change for 3 years. ${ }^{35}$

The main limitation of the present study derives from its design. This study was conducted as a prospective cohort, but if it was done randomly and blind, it would be more valid. However, we revealed that the two groups in terms of preoperative factors were quite similar and did not differ significantly. Another limitation is the lack of histological follow-up, which could show the actual alterations in the intensity of NASH.

\section{CONCLUSION}

Both bariatric surgeries (LSG and LGB) have been shown to substantially reduce BMI and improve the lipid profile, liver enzymes, and blood sugar in patients one year after surgery. The liver status in patients with NASH was also significantly enhanced on ultrasonography. Despite these modifications and enhancements, there is no substantial difference between the two types of surgery. Besides, total cholesterol, AST, ALT, LDL, and FBS were significantly associated with NASH grade in our study. It is suggested that further multicenter studies be conducted in the future with a greater sample size and as a randomized clinical trial with longer follow-ups to confirm the findings of this research and demonstrate their stability.

\section{ETHICAL APPROVAL}

There is nothing to be declared.

\section{CONFLICT OF INTEREST}

The authors declare no conflict of interest related to this work.

\section{REFERENCES}

1. Petta S, Di Marco V, Cammà C, Butera G, Cabibi D, Craxi A. Reliability of liver stiffness measurement in 
non-alcoholic fatty liver disease: the effects of body mass index. Aliment Pharmacol Ther 2011;33:1350-60. doi: 10.1111/j.1365-2036.2011.04668.x.

2. Kim HJ, Kim HJ, Lee KE, Kim DJ, Kim SK, Ahn CW, et al. Metabolic significance of nonalcoholic fatty liver disease in nonobese, nondiabetic adults. Arch intern Med 2004;164:2169-75. doi: 10.1001/archinte.164.19.2169.

3. Hormati A, Shakeri M, Iranikhah A, Afifian M, Sarkeshikian SS. Non-alcoholic fatty liver disease. Govaresh 2018;23:203-12.

4. Singh D, Das CJ, Baruah MP. Imaging of non alcoholic fatty liver disease: A road less travelled. Indian $J$ Endocrinol Metab 2013;17:990-5. doi: 10.4103/22308210.122606 .

5. Oh M, Winn J, Poordad F. diagnosis and treatment of nonalcoholic fatty liver disease. Aliment Pharmacol Ther 2008;28:503-22. doi: 10.1111/j.1365-2036.2008.03752.x.

6. Balsiger BM, Murr MM, Poggio JL, Sarr MG. Bariatric surgery: surgery for weight control in patients with morbid obesity. Med Clin North Am 2000;84:477-89. doi: 10.1016/s0025-7125(05)70232-7.

7. Carroll RW, Hall RM, Parry-Strong A, Wilson JM, Krebs JD. Therapeutic options in the management of obesity. $N$ Z Med J 2013;126:66-81.

8. Georgiadou D, Sergentanis TN, Nixon A, Diamantis T, Tsigris C, Psaltopoulou T. Efficacy and safety of laparoscopic mini gastric bypass. A systematic review. Surg Obes Relat Dis 2014;10:984-91. doi: 10.1016/j. soard.2014.02.009.

9. Maggard MA, Shugarman LR, Suttorp M, Maglione M, Sugerman HJ, Livingston EH, et al. Meta-analysis: surgical treatment of obesity. Ann Intern Med 2005;142:54759. doi: 10.7326/0003-4819-142-7-200504050-00013.

10. Mason ME, Jalagani H, Vinik AI. Metabolic complications of bariatric surgery: diagnosis and management issues. Gastroenterol Clin North Am 2005;34:25-33. doi: 10.1016/j. gtc.2004.12.008.

11. Wrzesinski A, Correa JM, Fernandes TMB, Monteiro LF, Trevisol FS, Nascimento RRd. Complications requiring hospital management after bariatric surgery. Arq Bras Cir Dige 2015;28:3-6. doi: 10.1590/S01026720201500 S100003.

12. Abraham A, Ikramuddin S, Jahansouz C, Arafat F, Hevelone N, Leslie D. Trends in bariatric surgery: procedure selection, revisional surgeries, and readmissions. Obes Surg 2016;26:1371-7. doi: 10.1007/s11695-015-1974-2.

13. Harnois F, Msika S, Sabaté JM, Mechler C, Jouet P, Barge $\mathrm{J}$, et al. Prevalence and predictive factors of non-alcoholic steatohepatitis (NASH) in morbidly obese patients undergoing bariatric surgery. Obes Surg 2006;16:183-8. doi: 10.1381/096089206775565122.

14. Feijó SG, Lima JMdC, Oliveira MAAd, Patrocínio RMV, Moura-Junior LG, Campos AB, et al. The spectrum of non alcoholic fatty liver disease in morbidly obese patients: prevalence and associate risk factors.
Acta Cir Bras 2013;28:788-93. doi: 10.1590/s010286502013001100008 .

15. Aldoheyan T, Hassanain M, Al-Mulhim A, Al-Sabhan A, Al-Amro S, Bamehriz F, et al. The effects of bariatric surgeries on nonalcoholic fatty liver disease. Surg Endosc 2017;31:1142-7. doi: 10.1007/s00464-016-5082-8.

16. Clark JM, Alkhuraishi AR, Solga SF, Alli P, Diehl AM, Magnuson TH. Roux-en-Y gastric bypass improves liver histology in patients with non-alcoholic fatty liver disease. Obes Res 2005;13:1180-6. doi: 10.1038/oby.2005.140.

17. Furuya Jr CK, De Oliveira CP, De Mello ES, Faintuch J, Raskovski A, Matsuda M, et al. Effects of bariatric surgery on nonalcoholic fatty liver disease: preliminary findings after 2 years. J Gastroenterol Hepatol 2007;22:510-4. doi: 10.1111/j.1440-1746.2007.04833.x.

18. Mathurin P, Hollebecque A, Arnalsteen L, Buob D, Leteurtre E, Caiazzo R, et al. Prospective study of the long-term effects of bariatric surgery on liver injury in patients without advanced disease. Gastroenterology 2009;137:532-40. doi: 10.1053/j.gastro.2009.04.052.

19. Musella M, Susa A, Greco F, De Luca M, Manno E, Di Stefano C, et al. The laparoscopic mini-gastric bypass: the Italian experience: outcomes from 974 consecutive cases in a multicenter review. Surg Endosc 2014;28:15663. doi: 10.1007/s00464-013-3141-y.

20. Reis CE, Alvarez-Leite JI, Bressan J, Alfenas RC. Role of bariatric-metabolic surgery in the treatment of obese type 2 diabetes with body mass index $<35 \mathrm{~kg} / \mathrm{m}^{2}$ : a literature review. Diabetes Technol Ther 2012;14:365-72. doi: 10.1089/dia.2011.0127.

21. Peterli R, Wölnerhanssen BK, Vetter D, Nett P, Gass M, Borbély Y, et al. Laparoscopic sleeve gastrectomy versus Roux-Y-gastric bypass for morbid obesity-3-year outcomes of the prospective randomized Swiss Multicenter Bypass Or Sleeve Study (SM-BOSS). Ann surg 2017;265:466-73. doi:10.1097/SLA.0000000000001929.

22. Milone M, Lupoli R, Maietta P, Di Minno A, Bianco P, Ambrosino P, et al. Lipid profile changes in patients undergoing bariatric surgery: a comparative study between sleeve gastrectomy and mini-gastric bypass. Int J Surg 2015;14:28-32. doi: 10.1016/j.ijsu.2014.12.025.

23. Vix M, Diana M, Liu KH, D’Urso A, Mutter D, Wu HS, et al. Evolution of glycolipid profile after sleeve gastrectomy vs. Roux-en-Y gastric bypass: results of a prospective randomized clinical trial. Obes Surg 2013;23:613-21. doi: 10.1007/s11695-012-0827-5.

24. Yang X, Yang G, Wang W, Chen G, Yang H. A meta-analysis: to compare the clinical results between gastric bypass and sleeve gastrectomy for the obese patients. Obes surg 2013;23:1001-10. doi: 10.1007/s11695-013-0938-7.

25. Benaiges D, Flores-Le-Roux J, Pedro-Botet J, Ramon J, Parri A, Villatoro M, et al. Impact of restrictive (sleeve gastrectomy) vs hybrid bariatric surgery (Roux-en-Y gastric bypass) on lipid profile. Obes Surg 2012;22:1268-75. doi: 10.1007/s11695-012-0662-8. 
26. Nguyen NT, Varela E, Sabio A, Tran CL, Stamos M, Wilson SE. Resolution of hyperlipidemia after laparoscopic Roux-en-Y gastric bypass. J Am Coll Surg 2006;203:249. doi: 10.1016/j.jamcollsurg.2006.03.019.

27. Asztalos BF, Swarbrick MM, Schaefer EJ, Dallal GE, Horvath KV, Ai M, et al. Effects of weight loss, induced by gastric bypass surgery, on HDL remodeling in obese women. J Lipid Res 2010;51:2405-12. doi: 10.1194/jlr. P900015.

28. Pihlajamäki J, Grönlund S, Simonen M, Käkelä P, Moilanen L, Pääkkönen M, et al. Cholesterol absorption decreases after Roux-en-Y gastric bypass but not after gastric banding. Metabolism 2010;59:866-72. doi: 10.1016/j. metabol.2009.10.004.

29. Younossi ZM, Page S, Rafiq N, Birerdinc A, Stepanova $\mathrm{M}$, Hossain N, et al. A biomarker panel for non-alcoholic steatohepatitis (NASH) and NASH-related fibrosis. Obes surg 2011;21:431-9. doi: 10.1007/s11695-010-0204-1.

30. Ong JP, Elariny H, Collantes R, Younoszai A, Chandhoke V, Reines HD, et al. Predictors of nonalcoholic steatohepatitis and advanced fibrosis in morbidly obese patients. Obes surg 2005;15:310-5. doi: 10.1381/0960892053576820.

31. Shi J, Xun Y, Hu C, Zhang L, Liu H, Lou G, et al. Clinical and histological features of non-alcoholic fatty liver disease. Zhonghua Gan Zang Bing Za Zhi 2009;17:812-6.

32. Uslusoy HS, Nak SG, Gülten M. Noninvasive predictors for liver fibrosis in patients with nonalcoholic steatohepatitis. World J Hepatol 2011;3:219-27. doi: 10.4254/wjh. v3.i8.219.

33. Burza MA, Romeo S, Kotronen A, Svensson PA, Sjöholm $\mathrm{K}$, Torgerson JS, et al. Long-term effect of bariatric surgery on liver enzymes in the Swedish Obese Subjects (SOS) study. PLoS One 2013;8:e60495. doi: 10.1371/journal. pone. 0060495 .

34. Papadia F, Marinari GM, Camerini G, Adami GF, Murelli F, Carlini F, et al. Short-term liver function after biliopancreatic diversion. Obes Surg 2003;13:752-5. doi: 10.1381/096089203322509336.

35. Keshishian A, Zahriya K, Willes EB. Duodenal switch has no detrimental effects on hepatic function and improves hepatic steatohepatitis after 6 months. Obes surg 2005;15:1418-23. doi: 10.1381/096089205774859290. 